\title{
Uma Avaliação da Criança como Sujeito Assujeitado no Processo Judicial
}

\author{
Jordana de Carvalho Pinheiro1, Sônia Margarida Gomes Sousa \\ Pontifícia Universidade Católica de Goiás, Goiânia-GO, Brasil
}

\section{RESUMO}

Mais de três décadas após a promulgação de legislações garantistas dos direitos das crianças, observa-se que a enorme distância entre o que se diz e o que se faz, no Estado Brasileiro, inviabiliza a garantia efetiva de seus direitos. Há, no texto das referidas leis, expectativa de oitiva de crianças, mas suas vozes seguem silenciadas, de forma que, em que pese a mudança de termos e nomes, seguem mantidas as velhas práticas ideológicas e distintivas de pessoas e classes, na sequência de um processo histórico e dialético de exclusão/inclusão. Neste estudo, de abordagem qualitativa e fundamentado nos pressupostos teóricos da Psicologia Sócio- Histórica de Vygotsky, foram realizadas pesquisas de cunho bibliográfico e empírico. A partir de entrevistas de roteiro não fechado com profissionais do Direito que atuam em processos judiciais que envolvem crianças, observou-se o assujeitamento das crianças e a distância que separa a positivação e o efetivo cumprimento dos direitos das crianças.

Palavras-chave: criança; sistema de justiça; justiça social; direitos civis; psicologia social.

\section{ABSTRACT - An assessment of the child as an objectified subject in the judicial process}

More than three decades after the enactment of guaranteeing children's rights, it is remarkable that the distance between what is said, especially based on the law, and what is done, by the Brazilian State, may jeopardize the effectiveness of guaranteeing their rights. Analyzing the content of these laws, there is an expectation concerning the hearing of children, however, their voices remain silent, so that despite the change of terms and names, the old ideological and distinctive practices continue, following a historical and dialectical process of inclusion-exclusion. In this qualitative study, based on the theoretical assumptions of the Socio-Historical Psychology of Vygotsky, bibliographical and empirical research was carried out. The analysis of semi-structured interviews with legal professionals who work with lawsuits involving children, showed an objectification of the children and the distance between the positivation and the effective fulfillment of the children's rights.

Keywords: child; justice administration system; social justice; civil rights; social psychology.

\section{RESUMEN - Una evaluación de los niños como individuos sujetos en el proceso judicial}

Más de tres décadas después de la promulgación de legislaciones que garantizan los derechos de los niños, se puede observar una gran distancia entre lo que se propuso y lo que se cumple en el Estado Brasileño, haciendo inviable la garantía efectiva de derechos de los menores. En el texto de las referidas leyes, hay expectativa de escucha de niños, pero sus voces siguen silenciadas, de modo que, a pesar del cambio de términos, se mantienen prácticas ideológicas arcaicas y distintivas de personas y clases, en la secuencia de un proceso histórico y dialéctico de inclusión-exclusión. En este estudio, con enfoque cualitativo y fundamentado en los presupuestos teóricos de la Psicología Socio-Histórica de Vygotsky, se realizaron investigaciones de cuño bibliográfico y empírico. A partir de entrevistas con profesionales del Derecho que actúan en procesos judiciales que involucran niños, se observó el asujeamiento de los niños y la distancia que separa el positivado y el efectivo cumplimiento de los derechos de los niños. Palabras clave: niños; sistema de justicia; justicia social; derechos civiles; psicología social.

Este estudo é resultado de um recorte da pesquisa intitulada "A escuta das crianças em juízo: uma análise dos significados atribuídos pelos profissionais do Direito à luz da Psicologia Sócio-Histórica" (Pinheiro, 2018), sustentada nas construções teóricas de Lev Vygotsky. Recortou-se, para este artigo, uma das reflexões emergentes da pesquisa: a percepção da criança como sujeito assujeitado no seio do processo judicial que a discute.
Motivada pela preocupação com o lugar ocupado pela criança no processo judicial, sobretudo com a participação daquela a quem o processo se destina ou deveria se destinar, esta pesquisa partiu da proposta de aprofundar a problematização e contribuir para a construção do conhecimento necessário para se apreender e compreender cientificamente o fenômeno psicossocial das relações entre a sociedade, a justiça e as crianças. Com o objetivo 
de evidenciar a distância percebida entre as disposições legais e as práticas dos tribunais, optou-se, neste estudo, por historiar a construção legislativa voltada à tutela dos direitos das crianças e dos adolescentes para, só então, apresentar alguns dos resultados obtidos da análise das falas dos sujeitos entrevistados.

Muito embora tenha sido a criança alçada à condição de sujeito de direitos no plano da lei, na transição entre as décadas de 1980 e 1990, observa-se que ainda persiste severa distância que a separa de efetivas políticas públicas e da plena garantia de seus direitos. Assim, seu assujeitamento se revela aos olhos daqueles que se dedicam a uma análise crítica de seu lugar social.

$\mathrm{Na}$ América Latina, as décadas de 1980 e 1990 foram decisivas para a mudança de paradigma em relação à compreensão do lugar social da criança, na sequência de um movimento que já ocorria globalmente. Mesmo antes da promulgação do Estatuto da Criança e do Adolescente em 1990 (Brasil, 1990b), o período era fértil em transformações e marcos legais. No Brasil, era idealizada a Constituição Cidadã, promulgada em 1988 e ainda vigente (Brasil, 2001). Na mesma época, em 1989, era promulgada, em Nova Iorque, a Convenção sobre os Direitos da Criança por parte da Organização das Nações Unidas (Brasil, 1990a). Referido texto fora aprovado pelo Congresso Nacional do Brasil no ano seguinte, quando também entrava em vigor o Estatuto da Criança e do Adolescente, promulgado pela Lei n. 8.069/90.

A modificação do paradigma constitucional, não somente do ponto de vista formal, mas especialmente em razão da mudança dos princípios orientadores da Constituição Federal de 1988, influenciou a transição da doutrina e codificação menoristas, até então norteadoras do Direito da Infância, para a doutrina da proteção integral. Seus pilares fundamentais são os princípios do melhor interesse da criança e da sua prioridade absoluta, estruturadores das legislações posteriores ao marco constitucional. A respeito dessa mudança de paradigma, Contini (2009) observa que a doutrina da proteção integral fez com que a criança passasse a ser vista como cidadã de direitos, em uma cidadania alicerçada por um tripé que envolve as conquistas históricas do homem acerca das garantias de seus direitos civis, políticos e sociais.

A questão da voz da criança, historicamente silenciada, e da garantia à sua participação social, despertou a atenção dos estudiosos da infância em todo o mundo, sobretudo a partir da promulgação da Convenção, marco fundamental no ordenamento jurídico internacional acerca dos direitos da criança. Seu revolucionário texto, antes de expor os acordos firmados pelos estados partes da Convenção, declarava expressamente, em preâmbulo, reconhecer a dignidade inerente e os direitos iguais e inalienáveis de todos os membros da família humana, proclamando direitos a proteção, cuidado e assistência especiais na infância e afirmando que, para o pleno e harmonioso desenvolvimento de sua personalidade, a criança deveria crescer no seio de sua família, sendo preparada para uma vida independente na sociedade (Brasil, 1990a). Nesse momento, nascia a denominada doutrina da proteção integral, que pretendia assegurar garantias à defesa e à proteção das crianças e dos adolescentes, zelando pelo que se chamou de seu desenvolvimento integral.

No que tange ao tripé formado pelos direitos civis, políticos e sociais, a Convenção sobre os Direitos da Criança da Organização das Nações Unidas os reconhecia como iguais, inalienáveis e pertencentes a todos os membros da família, ali incluídas as crianças. Já o ECA, que pode ser compreendido como catalisador da mudança de paradigma já citada, abandonou, ao menos sob o ponto de vista da norma, a ideia de menor, substituindo-a pelas ideias de criança e adolescente.

"No novo paradigma proposto pelo ECA, o foco principal passa por uma concepção de sociedade que se organiza por meio de mecanismos sociais, para incluir as crianças e os adolescentes num sistema que abarque a convivência social e o acesso às políticas públicas" (Contini, 2009, p. 298).

Amin (2015), dando enfoque constitucional ao direito material expresso na nova legislação para a criança e o adolescente, considera acertado o termo alcunhado para o conjunto de direitos fundamentais indispensáveis à formação integral deles. Isso porque, pelo termo estatuto, compreende-se todo o microssistema de efetivação do ditame constitucional de tutela ampla do público para o qual se volta.

Com tão relevantes conquistas, inaugurou-se um novo período na sociedade brasileira, de transformação social e de busca por garantia de direitos, assentado sob os princípios da cidadania, da igualdade e da dignidade da pessoa humana. Essa fase, para além de constitutiva de um novo marco normativo do direito da criança, foi marcante, também, para o desenvolvimento da Psicologia Social. Nesse contexto, insere-se, então, a Psicologia Sócio-Histórica, voltada a compreender os fenômenos sociais a partir de uma compreensão do "homem como ativo social e histórico" (Bock, 2001, p. 17), bem como da "sociedade como produção histórica dos homens". Assim como a compreensão da sociedade passa pela compreensão da infância, a construção dessa nova sociedade, democrática e cidadã, passa pela construção de novos paradigmas para a infância, socialmente discernida.

Dessa feita, a infância, como construção social que é, conta com a participação ativa das próprias crianças. Além de comporem uma categoria social, operam como verdadeiros atores sociais, que, portanto, participam, ou devem participar, ativamente da vida em sociedade. Para Prout e James (1990, p. 8-9), “as crianças são e devem ser vistas como atores na construção e determinação das suas próprias vidas sociais, das vidas dos que as rodeiam e das sociedades em que vivem. As crianças não são os sujeitos passivos de estruturas e processos sociais". 
Contudo, a contradição observada se assenta no fato de que, passados mais de 20 anos da publicação de "O Século perdido: raízes históricas das políticas públicas para a infância no Brasil”, em 1997, livro em que Irene Rizzini, tendo como base sua tese de doutorado, elabora "um pleito para que não se perdesse mais um século entre discursos e promessas que se esvaem e, retóricas que não se afinam com as ações" (Rizzini, 2011, p. 16), ainda se observa enorme distância entre o que se diz, especialmente na lei, e o que se faz, nas práticas cotidianas perpetradas pelas estruturas de poder do Estado brasileiro.

Essa contradição inviabiliza a garantia efetiva de direitos às crianças e aos adolescentes, historicamente esquecidos no Brasil, país marcado por uma perversa cultura de fortes raízes menoristas. Repetindo as indagações de Rizzini (2011, p. 71), elaboradas em seu prefácio à segunda edição, ainda é possível perguntar se as crianças de hoje vivem em melhores condições que as de ontem.

A partir dessa compreensão, afirma-se que a busca pela criança do lugar legítimo de sujeito de fala, de direitos e de ação (Sousa, 2012), ainda se encontra em construção. Isso a despeito do reconhecimento que já lhe fora outorgado pela letra fria da lei, evidenciando-se assim a primeira e grande contradição da dialética observada entre a lei e a sociedade.

Da análise atenta da realidade social em que estão inseridas as crianças, os questionamentos crescem: terão surtido efeitos todas as cartas, as convenções e os estatutos promulgados nas décadas da esperança? Terá a normatização sido suficiente para garantir os avanços almejados? Terá o império da lei cumprido sua missão no sentido da real efetivação dos direitos das crianças? Será hoje a doutrina da proteção integral, inaugurada no fim da década de 1980, uma realidade perceptível?

As respostas parecem desanimadoras. Há, no texto da Convenção sobre os Direitos da Criança (art. 12) e do Estatuto da Criança e do Adolescente (art. 47, \$6o, art. 100 , XII, art. $101, \$ 50$, art. $161, \$ 30$, art.179, art. 186), expectativa de oitiva de crianças e adolescentes. No entanto, suas vozes seguem silenciadas, pelo que é possível perceber que se mudam os termos e os nomes, mas se mantêm as velhas práticas ideológicas e distintivas de pessoas e classes.

Ao tratar da dialética constituída entre o processo histórico de exclusão e de inclusão perversa, Sawaia (2014, p. 8) busca "compreender as nuances das configurações das diferentes qualidades e dimensões da exclusão, ressaltando a dimensão objetiva da desigualdade social, a dimensão ética da injustiça e a dimensão subjetiva do sofrimento". Sobre o processo dialético de exclusão e inclusão social, a autora segue destacando a contradição que o constitui: inclui-se para excluir e, assim recursivamente, de modo que se percebe um verdadeiro caráter ilusório da inclusão expressa em lei. Compreendendo-a como perversa, a autora afirma que essa transmutação é condição da ordem social desigual em que as crianças, também elas, estão inseridas (Sawaia, 2014).

Nesse reconhecimento, nota-se que, apesar de devidamente positivados, os direitos das crianças continuam sendo negligenciados, ignorados, suplantados. Direitos os mais diversos e, especialmente, os que interessam a este trabalho, atinentes ao que se convencionou chamar de direito de participação. Este traduz direitos imanentes à criança e à sua altiva existência, como: o direito de ser sujeito, e não objeto, o direito de ser ouvida e compreendida, o direito de falar e ser atentamente escutada, o direito de participar ativamente, de opinar, de expressar o que pensa, o que acha, ou como faria se pudesse compartilhar o momento de tomada de decisões a seu respeito.

A respeito do reconhecimento da participação da criança pelo Estado, no âmbito dos processos judiciais ou administrativos, conforme previsão expressa no artigo 12 da Convenção sobre os Direitos da Criança, Santos, Costa e Faleiros (2016) contextualizam seu caráter protecionista, baseado na doutrina da proteção integral. Seria esse direito de participação uma verdadeira oportunidade de ser ouvida.

A lei, muito embora acerte ao expressar em seus códigos a garantia de direitos (à participação efetiva no processo, por exemplo), não consegue, de fato, garanti-los. Não se pode negar ser esse um movimento contraditório que muito interessa à Psicologia Sócio-Histórica: uma vez que se tem um direito, tem-se a expressão dele, sem, contudo, vislumbrar-se sua real efetivação.

É nesse contexto de evidente contradição que Sousa e Tavares (2012) questionam: "como uma política pública de ampla garantia de direitos sociais (direito à liberdade, ao tratamento humanizado, à educação e cidadania) - que historicamente se utiliza de práticas punitivas e coercitivas - pode se efetivar" (p. 95)? Ao buscarem delinear quais "contribuições a Psicologia Sócio-Histórica pode trazer para a efetivação dessas políticas” (p. 95-96), sobretudo para as políticas voltadas às crianças, destacam ser essa Psicologia que, ao reconhecer a criança como sujeito concreto, ativamente inserido em um contexto social que ajuda a produzir para além de ser produzido por ele, leva à compreensão da posição dessa criança em uma realidade mais ampla, apreendendo, então, seu processo de formação.

$\mathrm{Na}$ busca da compreensão da posição da criança em seu contexto social, ressalte-se a contribuição de Charlot (2013) sobre os significados ideológicos veiculados pela ideia de infância. Afirma que "socialmente, a criança é, antes de tudo, um ser dependente do adulto, à autoridade do qual está constantemente submetida" (p. 194). Para o autor, qualquer que seja a organização social observada, percebe-se a dependência da criança em relação ao adulto, até porque ela nasce e se desenvolve em um universo de adultos, por estes modelado, cujas estruturas, organização e modos de vida preexistem a ela. Nesse contexto, as crianças só conquistam, gradativa e progressivamente, 
sua autonomia, muito embora se postule, doutrinariamente, a dignidade específica do psiquismo infantil (Charlot, 2013).

No que se refere a essa dependência, inelutável, da criança em relação ao adulto, segundo Charlot (2013), é necessário se pensar a infância na forma de uma relação social recíproca, ou parceria social, entre a criança e o adulto. Para ele, "a criança é, para o adulto, certo tipo de parceiro social e vice-versa. É preciso, pois, pensar a infância em termos de relações sociais entre adultos e crianças" (Charlot, 2013, p. 195).

A respeito dessa relação que se deve construir socialmente, não se admitindo ser ela naturalmente posta, Sawaia (2014) analisa e reforça o traço perverso da dialética exclusão/inclusão que, por vezes, inebria a todos ao transparecer que o direito posto existe, quando ele não passa de mera retórica. Esse fenômeno se dá na medida em que, diante da existência da positivação, o Estado e as forças sociais se desresponsabilizam do processo de sofrimento que impingem aos excluídos, dentre eles as crianças.

Nesse contexto, pode-se considerar o silenciamento infligido às crianças que têm suas vidas discutidas em juízo uma espécie de sofrimento social. A respeito disso não há possibilidade de formulação íntima ou intersubjetiva, impondo-se a elas que aguardem a emancipação de suas vozes em uma escala social.

"É o indivíduo que sofre, porém, esse sofrimento não tem a gênese nele, e sim em intersubjetividades delineadas socialmente. Dessa forma, se os brados de sofrimento evidenciam a dominação oculta [...] das questões sociais dominantes em cada época histórica, em outras palavras, da vivência do mal que existe na sociedade" (Sawaia, 2014, p. 100-101).

Assim, ao se pensar na relação socialmente construída entre a criança e o adulto, evidencia-se a dominação oculta, denominada por Sawaia (2014), presente nas relações entre as crianças e o Poder Judiciário. Ora, essa compreensão de dependência da criança em relação ao adulto impacta, por certo, o direito de participação social da criança, tomado lato sensu, e de sua participação no âmbito da Justiça, estritamente considerado.

Sobre o âmbito da Justiça, em especial, é relevante citar Santos et al. (2016), quando afirmam, na mesma esteira do raciocínio de Charlot, haver "uma articulação da dominação masculina e adultocêntrica da família e do Poder Judiciário" (p. 47). Chamam a atenção, ainda, para a "perspectiva positivista da ação jurídica" (p. 45), que, certamente, intensifica ainda mais o conflito.

A respeito da construção de um saber psicológico na esfera do Judiciário, Bernardi (2015) alerta para a demarcação do lugar das crianças nos ambientes forenses. Trata-se de um lugar daqueles sujeitos sem voz, "que, por serem infantes, não falam nos autos processuais, e são, desse modo, ditos pelos outros, permanecendo ocultos nos processos a eles referidos" (p. 31).
Assim, a partir das práticas sociais e jurídicas, vê-se que a perspectiva menorista retorna, cotidianamente, na forma de sua dimensão histórica, não suplantada pela noção de justiça construída nos anais da Justiça. Explícita está, portanto, a contradição entre o caminho percorrido pela lei e a realidade dos fatos observados. Dessa forma, diz-se que, o Brasil abandonou a doutrina menorista apenas sob o ponto de vista formal, porque "de nada adianta a Constituição conceder-lhes a mais especial proteção, com prioridade absoluta, se nem a sociedade, nem as leis, nem juízes, promotores, defensores e advogados dão a eles merecida atenção" (Dias, 2017, p. 11).

A preocupação acerca de como as questões judiciais envolvendo crianças são constituintes e constitutivas dos sujeitos envolvidos no processamento e no julgamento de tais demandas, levou à busca, nesta pesquisa, das dimensões social e histórica que norteiam as práticas judiciais que se veem hoje multiplicadas.

Apesar de historicamente localizadas no lugar dos sem-fala, sendo conceituadas na negatividade daquilo que lhes falta, a fala lógica, assim considerada sob o ponto de vista dos adultos, as crianças, e o estudo sobre elas, têm muito mais a revelar. Para além das simplificações e reducionismos, a pesquisa que se propõe a dar voz à criança impõe a reflexão sobre o significado que ela e a infância têm no desvelamento do mundo, da sociedade e da história.

Da análise intentada, emergiu, como já delineado em linhas iniciais, uma forte categoria: a da criança como sujeito assujeitado no processo judicial, no sentido de que, embora ostente condição de sujeito, assim reconhecido pela lei, especialmente a CF, a Convenção e o ECA, desde o fim da década de 1980, permanece assujeitada. Fica em posição análoga à da objetalização com a qual se buscou romper com a transição da doutrina menorista para a doutrina garantista (Amin, 2015; Bernardi, 2015).

Com o fito de apresentar os resultados obtidos com a realização do levantamento bibliográfico e empírico, optou-se, neste artigo, pelo relato dos caminhos, legal e social, historicamente percorridos pela criança e pela compreensão que se tem de infância. Depois disso é que se buscou confirmar a distância entre as disposições legais e a dura realidade dos tribunais pátrios a partir da fala dos sujeitos que compõem uma rede de proteção à criança e ao adolescente, entrevistados na fase empírica da pesquisa.

\section{Método}

A pesquisa empírica, precedida e sustentada pela pesquisa bibliográfica, após a necessária aprovação pelo Comitê de Ética da universidade, deu-se por meio da realização de entrevistas individuais com oito profissionais do Direito, aos quais se apresentou o conteúdo do Termo de Consentimento Livre e Esclarecido, por todos assinado. Para selecionar os sujeitos participantes, 
foram enviadas cartas-convite aos profissionais atuantes no Direito das Famílias e da Infância de determinada comarca judiciária da Região Centro-Oeste do Brasil, com a detalhada apresentação da pesquisa. Acenaram positivamente ao convite os seguintes profissionais: um desembargador, uma juíza, uma procuradora, uma promotora de justiça, dois defensores públicos e duas advogadas.

Neste artigo, foram transcritas algumas falas de Gustavo e Murilo, membros da Defensoria Pública do Estado de Goiás (DPE), Geraldo e Rosana, membros do Tribunal de Justiça (TJ), Maria Augusta e Paula, membros do Ministério Público do Estado de Goiás (MP), e Adriana e Marcela, representantes da Ordem dos Advogados do Brasil Goiás (OAB). Note-se que os nomes utilizados neste texto são todos fictícios, em respeito à participação da identidade dos sujeitos participantes.

Para entrevistá-los, elaborou-se um roteiro de entrevista, não fechado, que possibilitasse que os sujeitos se expressassem livremente e acessassem seus repertórios de compreensão a respeito dos temas propostos para discussão: significados de infância e criança, sua participação social e sua escuta no processo, dificuldades de concretização dessa escuta e razões pelas quais ela não se dá. A delicadeza do tema discutido nesta pesquisa, que envolve, ao mesmo tempo, sujeitos socialmente tidos como frágeis, as crianças, e sujeitos socialmente fortes, poderosos e prestigiados, os profissionais do Direito que protagonizam as relações dentro dos tribunais, impôs a mesma delicadeza na sua análise e tratamento. Nesse ponto, é importante destacar que somente com uma leitura dialética dos objetos de estudo e referenciais teóricos foi possível comportar as visões de um estudo interdisciplinar, construído a partir de uma interface entre o Direito e a Psicologia, mas que acabou por agregar o conhecimento de diversas outras ciências, como a História e a Sociologia voltadas ao estudo da infância.

Assim, convém ressaltar que, na perspectiva vygotskiana (Vygotsky, 1989; 2000), é por meio da linguagem que o homem é constituído e constituinte de outros indivíduos, sendo fundamental o registro, bem como a análise, da linguagem falada. De forma que não só o que se diz, mas como se diz, de que se diz, com que ênfase se diz e o que deixa de ser dito importam.

Foi na escuta dos sujeitos entrevistados, concretamente tomados, com todas as suas singularidades, que se buscou escutar, também, aquilo que de mais amplo eles representavam: o próprio sistema de garantias de direitos, seus avanços e seus retrocessos, seus acertos e seus erros, suas conquistas e suas falhas. Essa proposta de análise se fortaleceu por meio da adoção do conceito do sujeito representante, de forma que o sujeito não se expressa sozinho, mas expressa toda a rede de proteção e atenção que representa (Sousa, 2001). A escolha, nesse caminho, e, mais do que isso, a exigência do próprio caminho trilhado, foi pelo enfrentamento das contradições, das tensões entre objetividade e subjetividade, entre particularidade e universalidade (Sawaia, 2014, 2015), entre o concreto e o abstrato que constituem, dialeticamente, o sujeito e o mundo (Sousa \& Tavares, 2012).

\section{Resultados}

Perguntados a respeito da criança e de sua participação no processo judicial, os entrevistados apresentaram os significados de criança objetalizada e de criança invisível. Esses subnúcleos foram reunidos em um núcleo de significação maior, que dá nome a este artigo, o de criança como sujeito assujeitado no processo judicial.

Adriana (OAB) e Gustavo (DPE) ressaltaram o caráter de objetalização com o qual as crianças figuram nos processos. Apresentando uma dupla compreensão da objetalização da criança, tomada no micro (pela família) e no macro (pelo Estado), evidenciaram "uma criança muito tratada como objeto pelos pais" e "uma cultura da criança como objeto de direito que está arraigada" na sociedade, no âmbito jurídico e, até mesmo, no Conselho Tutelar.

Para além da objetalização, Gustavo (DPE) destacou o antagonismo do assujeitamento da criança na sociedade com as disposições da Convenção e do ECA.

"Ainda a vejo como objeto, apesar do Estatuto da Criança e do Adolescente estar fazendo 27 anos. Ainda, a cultura da criança como objeto de direito está arraigada. [...] É muito difícil você trabalhar com o sujeito de direitos na medida que você só impõe, você não argumenta e você não negocia. Isso, em relação à criança e ao adolescente, na sociedade, ainda está muito arraigado como ideia de que a criança e o adolescente são objetos."

No mesmo sentido, de inobservância prática das disposições da lei e da doutrina da proteção integral, foi a fala de Murilo (DPE).

"Em que pese a evolução, no sentido de se superar a doutrina da situação irregular, ainda hoje a criança, no processo judicial, não é vista como um sujeito desse processo. Em um processo em que se decide sobre o futuro da criança ou a garantia da tutela de seus direitos fundamentais, muitas vezes a própria opinião dela não é ouvida e, mesmo quando ouvida, não é considerada da forma como deveria ser, da forma como preconiza o artigo 12 da Convenção Internacional sobre os Direitos da Criança e como preconiza o próprio ECA.”

Diferente da objetalização explícita, observou-se uma outra, mais velada, acobertada, oculta, em que se acredita ser a criança sujeito de direitos que, contudo, não ostenta de condições objetivas para exercê-los. Essa compreensão pôde ser percebida na fala de Geraldo (TJ), para quem a criança é compreendida "[...] como um sujeito de direitos, mas cujos direitos têm que ser exercidos por outrem": 
"Bem, aí nós temos que fazer a seguinte análise. As pessoas participam de um processo como titulares que são, dai a gente diz que, para o mundo do direito, pessoa é o sujeito de direitos, aquele que pode ter direitos. A criança é um sujeito de direito, mas sujeito de direito especial, porque ela não pode exercer o próprio direito no nome dela, ela tem que ter alguém para exercer esse direito dela."

Em relação à invisibilidade da criança, Rosana (TJ) afirmou enxergar a criança "com muita pouca voz [...] pouco ouvida. E ouvida não só verbalmente, [...] pouco enxergada. Muito pouco levada em conta”, relacionando multiplicadas facetas de invisibilidade. Essa também foi a constatação de Paula (MP) e de Marcela (OAB):

\section{"Pouco percebida. Muito embora eu atue em área de família e os processos em que eu atuo são aqueles em que, necessaria- mente, tem que haver criança ou adolescente. Mesmo nesses, a criança, principalmente, ou seja, aquela que tem até 12 anos incompletos, é pouco ouvida no processo. Sem dúvida. Muito pouco ouvida. Muito embora ela seja o sujeito para o qual aquele processo exista.}

Então eu vejo ela angustiada. E, ao mesmo tempo, invisível. Porque não é respeitada nas suas particularidades e necessidades que são únicas, por aquele momento que ela passa, por aquelas experiências que ela tem e, sobretudo, por aquelas pessoas com quem ela convive."

Essa criança invisível também pôde ser compreendida como inaudível, já que, conforme sete, dos oito entrevistados, ela não é vista, não é ouvida, não é percebida e não é considerada no processo judicial. Ela não é tida, ou como se pudesse dizer: ela não é, ela não está e ela não existe. Sendo assim, é objeto e não sujeito, já que não fala, não ouve e não é compreendida como pessoa que é pela família que a submete ao processo judicial e pelo Estado, a quem incumbe processar e julgar referido processo.

A respeito do verdadeiro foco do processo, Maria Augusta (MP) assim pontuou:

\section{"No curso do processo, a gente vai vendo, nitidamente, que começa no afã de proteger a criança e devagarzinho a mu- dança vai se revelando, no processo, esse embate das partes, quaisquer que sejam elas. E a criança começa a ocupar um outro espaço. Se ela começa como protagonista, ela já passa para um papel bem secundário. Ela só é chamada quando a situação vai perdendo o controle um pouco, daí se chama a criança de novo, para o foco da atenção. Mas não na criança em si. No assunto! O fato da criança ser o objeto daquela disputa."}

Da análise dos resultados, observou-se, assim, que, no exercício profissional, os chamados operadores do Direito decidem pela não escuta das crianças no íntimo dos processos judiciais que as discutem. Há, por certo, um discurso social, construído e vigente, que sustenta a prática desses operadores ou profissionais do Direito, de forma que os paradigmas do Direito não são seguidos pelo sistema, que deveria promover a garantia e a proteção desses direitos. Essa análise foi bem sintetizada por Murilo (DPE):

"Nessa atuação vejo ainda um ranço muito forte da doutrina da situação irregular, da doutrina menorista, a não introjeção dessa questão tão falada, do tratamento da criança e do adolescente como sujeito de direitos... É uma certa postura impositiva muito própria do poder Judiciário, mas, que, nessa área, deveria dar espaço a soluções não tão impositivas, mas de cunho restaurativo ou consensual".

Há certa angústia presente nessa fala, de um profissional que deseja ouvir as crianças sem, contudo, contar com um sistema que o possibilite fazê-lo. Essa não é uma questão local, mas expressiva de como as mudanças são lentas e de como as formas clássicas tendem a sempre retornar, tornando-se difícil o abandono das velhas práticas.

Os modos clássicos, de compreensão e enfrentamento das questões atinentes à infância e às crianças, se mantêm no tempo, muito embora o ordenamento jurídico, que sustenta formalmente o sistema garantidor de direitos, tenha avançado nas últimas três décadas. Como ensinam Rizzini, Rizzini, Naiff e Baptista (2007), o processo de mudança de paradigmas ocorre lentamente, em que pese o surgimento de novas leis e diretrizes de política familiar e comunitária.

Importa, nesse ponto, compreender como os núcleos de significação perpassam os sujeitos, mantendo na compreensão deles as fortes raízes menoristas que, formalmente, já têm, ou deveriam ter, lugar reservado no passado. Historicamente, no Brasil, a criança nunca ocupou, e ainda não ocupa, um lugar social de verdadeiro respeito aos seus direitos. O discurso vigente é fortemente arraigado e os sujeitos envolvidos na tomada de decisões que envolvem crianças cegam-se de certezas que, por vezes, não cabem mais.

Da realização da pesquisa empírica e da análise dos núcleos de significados atribuídos pelos profissionais do Direito a respeito da criança no processo judicial, foi possível enxergar concretamente o que, abstratamente, percebia-se: a existência de grande distância entre as transições legal e social do lugar ocupado pela criança. Assim, a pesquisa trouxe algumas respostas e elucidou algumas questões: (a) não se deixa de ouvir por desconhecimento da lei, mas por falta de mecanismos que exijam a oitiva, de um sistema que a possibilite e, ainda, por falta de articulação de conhecimentos de diversas matizes ou ausência de equipe técnica que o faça; (b) assim, sabe-se necessária a oitiva, mas, mesmo assim, insiste-se em reservar à criança o lugar dos sem-fala; (c) há a significação clara e 
evidente de que a criança ainda ocupa posição desprivilegiada e fragilizada na sociedade brasileira, compreensão essa praticamente naturalizada; (d) não se tem, de fato, um sistema eficaz e efetivo, que prime pela criança e pela família, muito embora exista previsão em legislação nacional e internacional.

Não se pode ignorar o fato de que muito mudou com a transição da legislação menorista para a doutrina da proteção integral. Contudo, prevalece a percepção de que às crianças cujas vidas são discutidas em juízo poucas vezes ou quase nunca é oportunizado o direito de fala, participação e opinião. Dessa forma, escancara-se uma grande distância entre as disposições do ordenamento jurídico brasileiro, que se diz primar pela criança e protegê-la, e as práticas profissionais e institucionais perpetradas pelos operadores do Direito e órgãos responsáveis pela observância e cumprimento da ordem jurídico-legal.

\section{Considerações Finais}

Embora delicados e contraditórios, o tema e a realização da pesquisa mostram-se prementes e relevantes. O tema porque, de fato, as crianças têm tido suas vidas discutidas em juízo, ocupando, no sistema judiciário um lugar ainda incerto e conflituoso, um lugar daqueles sem lugar. A realização da pesquisa porque o assunto, embora importante, ainda resta pouco explorado academicamente no país, deixando não só o ambiente acadêmico carente de novas proposições a respeito da escuta das crianças em juízo, como também os profissionais que com essa escuta atuam ou deveriam atuar (uma vez que ficam desprovidos de recursos teóricos, de novas técnicas e possibilidades, sem saber como entender, proceder e decidir as questões que envolvem crianças).

Entende-se que somente pela leitura dialética dos objetos estudados torna-se possível analisar tamanha complexidade, visto que o materialismo histórico e dialético trabalha com as antíteses com o fito de produzir uma síntese, expondo e contrapondo as tensões entre as constituições objetivas e subjetivas. Na busca por alcançar tamanha complexidade, necessário se faz o enfrentamento das contradições, das tensões entre objetividade e subjetividade, entre particularidade e universalidade, entre o concreto e o abstrato que constituem, dialeticamente, o sujeito e o mundo, na busca pelo princípio da totalidade, o qual Sawaia (2015) menciona. Assim, entende-se que esse desafio pode ser enfrentado mediante a escolha de uma abordagem interdisciplinar, que permita a articulação das construções das ciências que se ocupam do estudo da criança, sempre à luz da dialética.

Para além da interdisciplinaridade como forma de realização acadêmica, acredita-se que os profissionais do Direito precisem tomar emprestado as construções das outras ciências, a fim de expandirem suas compreensões, ampliarem seus juízos, duvidarem de suas certezas, fortalecerem suas técnicas e se aperfeiçoarem no trato diário das crianças que lhes são apresentadas para conhecer, opinar, processar e julgar. Sem uma abordagem interdisciplinar, o que se vê são profissionais amedrontados, que não sabem ao certo como entender a infância, em abstrato, e o que fazer com a criança que lhes aparece para processar e julgar, em concreto.

Nesse sentido, mais uma vez, há necessidade de se caminhar. É de suma importância que os profissionais do Direito encarregados do processamento e das decisões dos processos que tratam de crianças se conscientizem que o Direito e seus postulados, sozinhos, não fornecem todos os caminhos e respostas. Assim como a Psicologia Jurídica, sozinha, não o faz. Há, por certo, distanciamentos e aproximações entre as Ciências. Contudo, há, para além das divisões, dos retalhos, dos recortes e distanciamentos, aproximações, convergências, interlocuções e diálogos que se fazem necessários no cotidiano daqueles que estudam e atuam com crianças. $\mathrm{O}$ tema exige uma densa articulação de compreensões que trabalhem, em cooperação, para melhores desfechos, mais humanos, mais afetuosos e mais dignificantes da criança e da família.

É imperativo que se compreenda e cumpra, não no futuro, mas no presente, o estatuto de sujeito de direitos que as crianças possuem, sobretudo as crianças judicializadas, de modo a enxergar a perpetração de injustiças e de promover a dignificação do tratamento a elas dispendidos. Há que se considerar o enorme contingente de ações judiciais que discutem as vidas das crianças e tramitam nas Varas de Família e Juizados da Infância do país. Torna-se relevante reconhecer a premente necessidade de se concretizar, nos planos prático-teóricos, profissionais e institucionais, a legislação da proteção integral da criança, que a consagra como sujeito de direitos, e não mais objeto, vigente há quase 30 anos e ainda tão desconhecida do cotidiano dos tribunais.

\section{Referências}

Amin, A. R. (2015). Princípios orientadores do direito da criança e do adolescente. Em K. R. F. L. A. Maciel (Orgs.). Curso de direito da criança e do adolescente: Aspectos teóricos e práticos (8ed., pp. 50-51). São Paulo, SP: Saraiva.

Bernardi, D. C. F. (2015). A construção de um saber psicológico na esfera do Judiciário paulista: um lugar falante. Em E. T. Fávero, M. J. R. Melão, \& M. R. T. Jorge (Orgs.). O serviço social e a psicologia no judiciário: Construindo saberes, conquistando direitos (5ed., p. 31). São Paulo, SP: Cortez. 
Bock, A. M. B., Furtado, O., \& Teixeira, M. L. T. (2001). Psicologias: Uma introdução ao estudo de psicologia (13ed., p. 17). São Paulo, SP: Editora Saraiva.

Brasil (1990a). Decreto n. 99.710. Promulga a Convenção sobre os Direitos da Criança. Brasília, DF: Diário Oficial da União. Recuperado de www.planalto.gov.br/ccivil_03/decreto/1990-1994/d99710.htm

Brasil (1990b). Lei n 8.069. Dispõe sobre o Estatuto da Criança e do Adolescente e dá outras providências. Brasília, DF: Diário Oficial [da] República Federativa do Brasil. Recuperado de www.senado.gov.br/ccivil_03/leis/2002/L10406.htm

Brasil (2001). Constituição da República Federativa do Brasil de 1988. [Coleção Saraiva de Legislação]. (21ª ed.). São Paulo, SP: Saraiva.

Charlot, B. (2013). A mistificação pedagógica: Realidades sociais e processos ideológicos na teoria da educação. (M. J. A. Ferreira, trad.). São Paulo: Cortez. (13ed., p. 17). São Paulo, SP: Editora Saraiva.

Contini, M. L. J. (2009). Psicologia e a construção de políticas públicas voltadas à infância e à adolescência: contribuições possíveis. Em A. M. B. Bock (Org.). Psicologia e o Compromisso Social. (2.ed., p. 298). São Paulo, SP: Cortez.

Dias, M. B. (2017). Filhos do afeto. (2.ed.). São Paulo, SP: Editora Revista dos Tribunais.

Pinheiro, J. C. A escuta das crianças em juízo: Uma análise dos significados atribuídos pelos profissionais do Direito à luz da Psicologia Sócio-Histórica (Dissertação de mestrado). Pontifícia Universidade Católica de Goiás, Goiás. Recuperado de http://tede2.pucgoias.edu.br:8080/ handle/tede/3963

Prout, A., \& James, A. (1990). Constructing and reconstructing childhood: Contemporary issues in the sociological study of chilhood. Londres: The Falmer Press.

Rizzini, I. (2011). O século perdido: Raízes históricas das políticas públicas para infância no Brasil. (3.ed.). São Paulo, SP: Cortez.

Rizzini, I., Rizzini, I., Naiff, L., \& Baptista, R. (2007). Acolhendo crianças e adolescentes: Experiências de promoção do direito à convivência familiar e comunitária no Brasil. (2.ed.). São Paulo, SP: Cortez.

Santos, B. R., Costa, L. F., \& Faleiros, V. P. (2016). Depoimento especial: Relação entre as implicações psicossociais e jurídicas. Em L. Potter \& M. V. Hoffmeister (Orgs.). Depoimento especial de crianças e adolescentes: Quando a multidisciplinaridade aproxima os olhares. (pp. 39-56). Porto Alegre, RS: Livraria do Advogado Editora.

Sawaia, B. B. (2014). As artimanhas da exclusão: Análise psicossocial e ética da desigualdade social. (14ª . ed.). Petrópolis, RJ: Vozes.

Sawaia, B. B. (2015). Psicologia Sócio-histórica: Interdisciplinaridade e transformação social - uma relação teórica com Vigotski sem fidelidade opressiva. Em S. T. F. Martin. Psicologia Sócio- histórica e contexto brasileiro: Interdisciplinaridade e transformação social (pp. 10-25). Goiânia, GO: Editora da PUC Goiás;

Sousa, S. M. G. (2001). Prostituição infantil e juvenil: Uma análise psicossocial do discurso de depoentes da CPI (Tese de doutorado em Psicologia Social). Pontifícia Universidade Católica de São Paulo, São Paulo. Recuperado de https://tede2.pucsp.br/handle/handle/17392

Sousa, S. M. G. (2012). O método e a metodologia da pesquisa. Em S. M. G. Sousa \& M. I. C. Moreira. Atendimento psicossocial de crianças e adolescentes em situação de abuso sexual (pp. 17-36). Goiânia, GO: Cânone Editorial.

Sousa, S. M. G., \& Tavares, R. C. (2012). As contribuições da psicologia sócio-histórica para as políticas públicas da área da infância, adolescência e juventude. Em J. C. Chaves. Psicologia social e políticas públicas: Contribuições e controvérsias (pp. 83-98). Goiânia, GO: Editora da PUC Goiás.

Vygotsky, L. S. (1989). Pensamento e linguagem. São Paulo, SP: Martins Fontes.

Vygotsky, L. S. (2000). Manuscrito de 1929. Educação \& Sociedade, 21(71), 21-44. doi: 10.1590/S0101-73302000000200002

\section{Sobre as autoras}

Jordana de Carvalho Pinheiro é advogada, mestre em Psicologia Social pela Pontifícia Universidade Católica de Goiás (PUC-Goiás) e professora em cursos jurídicos de especialização. Tem experiência em Direito das Famílias e das Crianças. Estuda a participação da criança no processo judicial.

Sônia Margarida Gomes Sousa é psicóloga, mestre e doutora em psicologia social pela Pontifícia Universidade Católica de São Paulo (PUC-SP), professora titular de psicologia da escola de ciências sociais e da saúde da Pontifícia Universidade Católica de Goiás (PUC-Goiás) e pró-reitora de graduação na mesma instituição. Estuda os aspectos psicossociais da infância, da adolescência e da juventude. 